Notes and miscellanea

\section{Interaction between drugs and solvents as a cause of fatty change in the liver?}

Occupational exposure to chlorinated and nonchlorinated solvents has been associated with liver dysfunction. ${ }^{12}$ The levels of exposure have usually been high, but experimental evidence indicates that interaction may occur between different solvents at relatively low levels of exposure. ${ }^{34}$ The following three case histories suggest that drugs and solvents may also interact.

\section{Case 1}

A 52-year-old man with no history of gastrointestinal disease suffers from lumbago, for which he took acetylsalicylic acid (Paraflex comp). He drank less than $30 \mathrm{cl}$ of alcohol a month. As an orthopaedic shoemaker (1946-76) he was exposed mainly to acetone, but also to thinner, chloroform, trichloroethylene, and tetrahydrofurane. In 1967 he had raised $\gamma$-GT $(2 \cdot 16-2.32 \mu \mathrm{kat} / \mathrm{l}$, normal $<0.70)$, and three years later also increased ALAT (0.81 $\mu$ kat $/$, normal $<0.70$ ). A liver biopsy specimen showed "liver with moderate centriacinar fatty change and pronounced siderosis."

\section{Case 2}

Another 52-year-old man with previous hospital treatment for cholescystectomy, operation for a slipped disc, and myocardial infarction received digoxin (Lanacrist), verapamil (Isoptin), and paracetamol (Lunedon), but took no alcohol. As a painter (1950-73) he was exposed to thinner. In 1974 he had persistent increase in ALAT (0.72-1.34 $\mu$ kat $/ 1$, normal 0.08-0.58) and ASAT (1.94-2.20 $\mu$ kat $/ 1$, normal $0 \cdot 08-0 \cdot 84$ ). A liver biopsy specimen in 1974 showed "pronounced fatty change in the liver."

\section{Case 3}

A 42-year-old man with high blood pressure and cardiac enlargement but no previous history of

Received 8 June 1981

Accepted 2 July 1981 gastrointestinal disease took digoxin (Lanacrist), hydralazine (Apresolin), and propanolol (Inderal). He drank under $30 \mathrm{cl}$ of alcohol a month. He was a painter (1964-76) exposed mainly to xylene. In 1976 he had raised ASAT (1.03-1.31 $\mu \mathrm{kat} / \mathrm{l}$, normal $<0.70)$, and ALAT $(2 \cdot 22-2.86 \mu \mathrm{kat} / \mathrm{l}$, normal $<0.70$ ) but normal $\gamma$-GT. A liver biopsy specimen showed "fatty change in the liver."

When considering increases in aminotransferases, alcohol consumption always has to be considered. It is, however, well known that people with alcohol problems often understate their consumption; on the other hand, they appear to consume less alcohol than those who admit their drinking. ${ }^{5}$

In all three cases drugs had been taken. Paraflex comp contains dextropropoxyphene $(45 \mathrm{mg})$ which, in animal tests, has produced hepatic enlargement and fatty change in the liver. ${ }^{6}$ There are case reports where a daily intake of $130 \mathrm{mg}$ of dextropropoxyphene has caused an increase in liver enzymes, but liver biopsy specimens showed no fatty changes.? Lunedon contains paracetamol, which may cause liver damage. 8 Neither Apresolin, Lanacrist, nor Inderal are reported hepatotoxins. ${ }^{9}$ There are reports, however, of hypertension giving rise to liver dysfunction, but this seems to be related to alcohol consumption rather than to the hypertension itself. 1011

As to the solvents in use, chloroform is a known hepatotoxin and could perhaps explain the picture in one of the cases. In solvent sniffers exposure to thinner has resulted in fatty changes in the liver, ${ }^{12}$ and exposure to xylene is known to produce mild hepatic steatosis. ${ }^{13}$

In conclusion, it seems difficult to explain the fatty changes in the liver in these patients only from the use of alcohol. Solvents could be a cause, or the combination of toxic substances. Potentiation between alcohol and solvents has been shown in animal experiments, ${ }^{34}$ but the combination of medical preparations and solvents has not been properly studied. It seems reasonable, therefore, in the investigation of liver dysfunction of unknown aetiology to consider the possibility of exposure to solvents in combinations not only with alcohol but also with the use of drugs.

C EDLING

Department of Occupational Medicine, University Hospital, Linköping, Sweden

\section{References}

${ }^{1}$ Powell-Jackson P, Davies M. Occupational liver disease. The Practitioner 1979;223:67-70. 
${ }^{2}$ Axelson O, Gustavson J. Some hygienic and clinical observations on styrene exposure. Scand J Work Environ Health 1978;4:215-9.

${ }^{3}$ Cornish H, Adefuin J. Ethanol potentiation of halogenated aliphatic solvent toxicity. Am Ind Hyg Assoc $J$ 1966;27:57-61.

- Traiger G, Plaa G. Chlorinated hydrocarbon toxicity. Potentiation by isopropylalcohol and acetone. Arch Environ Health 1974;28:276-8.

${ }^{5}$ Orrego H, Blendis LM, Blake JE, Kapor BM. Reliability of assessment of alcohol intake based on personal interviews in a liver clinic. Lancet 1979;ii:1354-6.

${ }^{6}$ Emmerson JL, Gibson WR, Harris PN. Short-term toxicity of propoxyphene salts in rats and dogs. Toxicol Appl Pharmacol 1971;19:452-70.

${ }^{7}$ Lee TH, Rees PJ. Hepatotoxicity of dextropropoxyphene.
Br Med J 1977;ii:296.

${ }^{8}$ Prescott LF, Wright N, Roscoe P, Brown SS. Plasmaparacetamol half-life and hepatic necrosis in patients with paracetamol overdosage. Lancet 1971;1:519-22.

${ }^{9}$ Dukes MNG (ed). Side effects of drugs annual, 3. Amsterdam: Excerpta Medica 1979.

${ }^{10}$ Ramsay LE. Liver dysfunction in hypertension. Lancet 1977;ii:111-4.

11 Beevers DG. Alcohol and hypertension. Lancet 1977;ii: 114-5.

${ }^{12}$ Edh M, Selerud A, Sjöberg C. Death and sniffing. A report on 63 cases. Svenska Läkartidn 1973;70:3949-59.

${ }^{13}$ Zimmerman HJ. Hepatotoxicity: the adverse effects of drugs and other chemicals on the liver. New York: Appleton-Century-Crofts, 1978:303-18. 